\title{
National Ignition Facility Sub-System Design Requirements \\ Computer System SSDR 1.5.1
}

\author{
J. Spann \\ P. VanArsdall \\ E. Bliss
}

September 5, 1996

This is an informal report intended primarily for internal or limited external distribution. The opinions and conclusions stated are those of the author and may or may not be those of the Laboratory.

Work performed under the auspices of the U.S. Department of Energy by the Lawrence Livermore National Laboratory under Contract W-7405-Eng-48. 


\section{DISCLAIMER}

This document was prepared as an account of work sponsored by an agency of the United States Government. Neither the United States Government nor the University of California nor any of their employees, makes any warranty, express or implied, or assumes any legal liability or responsibility for the accuracy, completeness, or usefulness of any information, apparatus, product, or process disclosed, or represents that its use would not infringe privately owned rights. Reference herein to any specific commercial product, process, or service by trade name, trademark, manufacturer, or otherwise, does not necessarily constitute or imply its endorsement, recommendation, or favoring by the United States Government or the University of California. The views and opinions of authors expressed herein do not necessarily state or reflect those of the United States Government or the University of California, and shall not be used for advertising or product endorsement purposes.

This report has been reproduced directly from the best available copy.

Available to DOE and DOE contractors from the Office of Scientific and Technical Information

P.O. Box 62, Oak Ridge, TN 37831

Prices available from (615) 576-8401, FTS 626-8401

Available to the public from the

National Technical Information Service

U.S. Department of Commerce

5285 Port Royal Rd.,

Springfield, VA 22161 


\title{
National Ignition Facility
}

\section{Sub-System Design Requirements}

\author{
Computer System \\ SSDR 1.5.1 \\ Revision 2 \\ 5 September 1996
}

Prepared by:

J. Spann, Computer System Team Leader

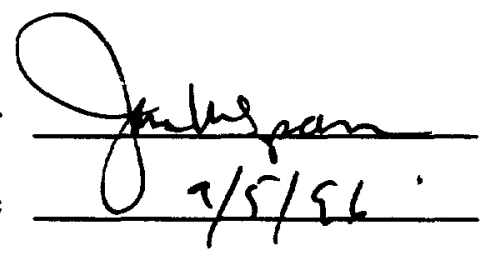

P. VanArsdall, Integrated Computer Controls

Date

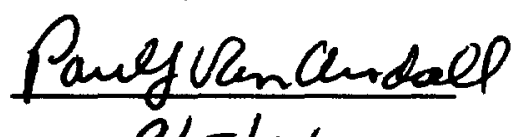

E. Bliss, System Controls System Engineer

Date

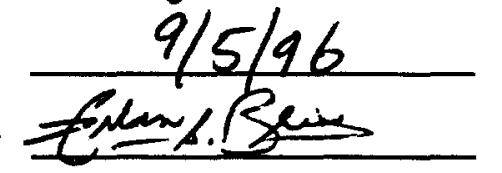

Date

$10 / 5 / 96$

Special Equipment Engineering Approval:

R. Sawicki, NIF Associate Project Engineer

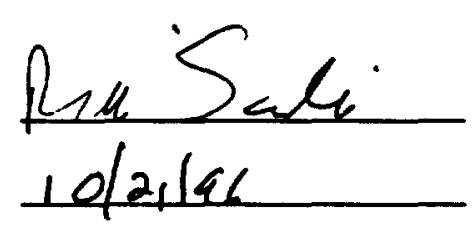

Engineering Review Board Approval:

s. Kumpan, NIF Project Engineer S.A. Karen

Approval Date $16 / 21 / 96$ 


\section{Table of Contents}

\section{Paragraph}

1.0

2.0

2.1

2.2

2.3

2.4

2.5

2.6

3.0

3.1

3.1.1

3.1 .2

3.1.2.1

3.1.2.2

3.1.2.3

3.1.2.4

3.1.2.5

3.1 .3

3.1 .4

3.2.00

3.2 .01

3.2 .02

3.2 .03

3.2.03.1

3.2.03.2

3.2.04

3.2 .05

3.2 .06

3.2.07

3.2 .08

3.2 .09

3.2.10

3.2.11

3.2 .12

3.2 .13

3.2 .14

3.2 .15

3.2 .16

3.2 .18

3.2.19

3.2 .20

3.2 .21

3.2 .22

3.2 .23

3.2 .24

3.2 .25

3.2 .26

3.2 .27

3.2 .28
Title

Scope

Applicable Documents

Applicable NIF Project Documents

Applicable US Government Orders and Standards

Applicable National Consensus Codes and Standards

Applicable LLNL Standards

Supporting Documentation Standards

References

Requirements and Verification

System Definition

System Description

System Diagrams

Layered Controls Architecture

Computer System Network

Control Room Layout

Computer Room Layout

Operator Console Layout

System Interfaces

Major Subsystems

Functional Requirements

Console Ergonomics

Computer System, Operating System

Computer Networks

Facility Wide Computer Network

Computer Network, Safety Systems

Optical Communications Safety

Computer System and Network Reliability

GUI Support

Network Performance, Average Latency

Network Performance, Maximum Response Time

Network Performance, Sustained Data Rate

Ethernet Loading

GUI Computing Capacity, Interactive Device Update Performance

GUI Computing Capacity, Alarm and Exception Report Performance

GUI Computing Capacity, Broad View Update Performance

Configuration

Shot Data Disk Storage Capacity

Shot Data On-line and Archived

Control Room Console Configuration

Console Graphics Standard

Console System Flexibility

Network Backbone

LAN Subnets (Ethernet)

Lower-Level Computer Attachment to LAN

Ethernet Protocol

Graphics Software

Computer Availability

Computer System QA Level Requirements

Computer Availability, cold start 
3.2 .29

3.2 .29 .1

3.2.29.2

3.2.29.3

3.2 .29 .4

3.2.29.5

3.2 .30

3.2.30.1

3.2.30.2

3.2.30.3

3.2.30.4

3.2 .31

3.2 .32

3.2 .33

3.2.34

3.4

3.4 .1

3.4 .2

6.0
Computer System and Network, Lifetime, Replaceability and RAM Computer System and Network, Lifetime Computer System and Network, Replaceability

Computer System and Network, Reliability

Computer System and Network, Availability

Computer System and Network, Maintainability

Environmental Requirements/EMI

Environmental Requirements, Temperature and Humidity

Environmental Requirements, Plenum Approved/CL2 Cables

Environmental Requirements, EMI Fields

Environmental Requirements, Ionizing Radiation

Human Factors

Recovery From Abnormal Event

Documentation and Records

Computer Security

Logistics

Maintenance

Spares

Revision Record 


\section{$1.0 \quad$ Scope}

This System Design Requirement document establishes the performance, design, development, and test requirements for the Computer System, WBS 1.5.1 which is part of the NIF Integrated Computer Control System (ICCS). This document responds directly to the requirements detailed in ICCS (WBS 1.5) which is the document directly above.

\subsection{Applicable Documents}

This section lists DOE orders, codes, and standards which are applicable to the NIF Integrated Computer Control System. The applicable portions of these documents apply. Applicable LLNL standards are being considered contingent upon the decision of final site selection.

\section{$2.1 \quad$ Applicable NIF Project Documents}

National Ignition Facility Functional Requirements and Primary Criteria, Revision 1.4, Mar 1996. (FRPC)

\subsection{Applicable US Government Orders and Standards}

(flowdown from SDR004=fd, no-flowdown=nfd)

US. Government DOE General Orders:

DOE 5700.6C-Quality Assurance (fd)

US. Government DOE Orders relating to Safeguards and Security:

DOE Order 1360.2B, Unclassified Computer Security Program (fd)

DOE Order 5300.4D, Telecommunications: Protected Distribution Systems (fd)

DOE Order 5639.6, Classified Computer Security Program (fd)

\subsection{Applicable National Consensus Codes and Standards}

Safety Standards:

National Fire Protection Association (NFPA)-70 National Electrical Code (fd)

ANSI C2-1990, National Electric Safety Code (fd)

Software and Electronic Standards:

Ethernet IEEE-802.3 Local Area Network for Data Communications

FDDI Fiber Distributed Data Interface, ANSI Standard X3.139-1987

RS-232C EIA Serial interface standard

RS-485 EIA Multi-drop serial interface standard

IEEE-488 Standard Digital Interface for Programmable Instrumentation, ANSI/IEEE Std

488.1-1987 and ANSI/IEEE Std 488.2-1987

VMEbus

RS-170

Ada 83

Ada 95

$\mathrm{X} 11$

OSF/Motif

IEEE-1014

Postscript

EIA Video interface standard

ANSIMIL-STD-1815A-1983, programming language

International Standard ANSI/ISO/IEC-8652:1995, January 1995

POSIX

TCP/IP

X Window System, Version 11, windows graphics standard, MIT X Consortium

OSIISO

OSF/DCE

OSF/DME

Motif graphical user interface, Open Systems Foundation

Text and graphics printing language, Adobe Systems Inc.

IEEE-1003 portable application programming environment

Protocol stack for network communications

Open Systems Interconnect protocol stack for network communications

Distributed Computing Environment, Open Systems Foundation

Distributed Management Environment, Open Systems Foundation

\subsection{Applicable LLNL Standards}

LLNL NIF Grounding Plan, L-17346-1 


\subsection{Supporting Documentation Standards}

Instrument Society of America, ISA-S5.1, Instrumentation Symbols and Identification

Instrument Society of America, ISA-S5.2, Binary Logic Diagrams for Process Operations

Instrument Society of America, ISA-S5.3, Graphics Symbols for Distributed Control/Shared Display

Instrumentation, Logic and Computer Systems

Instrument Society of America, ISA-S5.4, Instrument Loop Diagrams

Instrument Society of America, ISA-S5.5, Graphics Symbols for Process Displays

ANSIIEEE Std 730.1-1989, IEEE Standard for Software Quality Assurance Plans

Software Guidelines Standards, Practices, and Conventions (Final DRAFT), Applications Development

Department, Lawrence Livermore National Laboratory, August 10, 1992

ANSI/IEEE Std 830-1984, IEEE Guide for Software Requirements Specification

ANSI/IEEE Std 1016-1987, IEEE Recommended Practice for Software Design Descriptions

ANSI/IEEE Std 828-1983, IEEE Standard for Software Configuration Management Plans

ANSI/IEEE Std 982.1-1988, IEEE Standard Dictionary for Measures to Produce Reliable Software

ANSI/IEEE Std 982.2-1988, IEEE Guide for the Use of IEEE Standard Dictionary of Measures to Produce

Reliable Software

The Software Productivity Consortium, Ada Quality and Style Guidelines for Professional Programmers

ANSI/IEEE Std 1063-1987, IEEE Standard for Software User Documentation

\subsection{References}

NIF-LLNL-95-044/L-15958-2, National Ignition Facility Quality Assurance Program Plan, September 1995

NIF-LLNL-94-017/L-15958-5, NIF Ancillary Software Quality Assurance Plan, January 12, 1994

\subsection{Requirements and Verification}

\subsection{System Definition}

\subsubsection{System Description}

The computer system and network architecture, shown in paragraph 3.1.2.2 provides control functions and graphical user interfaces wherever needed in the facility to meet the dual requirements of centralized controls for experiments and remote controls for construction and maintenance. The upper-level computer system is shown attached to the Fiber Distributed Data Interchange (FDDD) high performance network whereas the lower-level system is shown attached to less expensive local Ethernets. (Choice of actual network hardware are a design decision and shall be made based on network traffic analysis.) Processors located anywhere on the network can access any other using standard communication protocols. Computers on the network access data files from a central operations file server. The server is a dual-host configuration that shares the work load and converts to a single server (with somewhat reduced performance) in the event of breakdown. A separate software file server and set of developer workstations segregates software engineering activities from on-line operations until new updates are released.

Graphical-User Interface (GUI) operator controls are implemented with graphics workstations adhering to the XWindows and Motif graphics standards. Four consoles are provided, one for each of the major subsystems. Consoles in the control room offer four display screens and two keyboards with the capability of TV image display. A two screen console serves the shot director. An auxiliary console supplies extra maintenance and calibration support for all subsystems.

The lower-level network attaches to several types of FEP. Local control of FEP systems is achieved by displaying GUI software on $\mathrm{X}$ terminals placed in the same equipment racks as the processors.

\subsubsection{System Diagrams}




\subsubsection{Layered Controls Architecture}

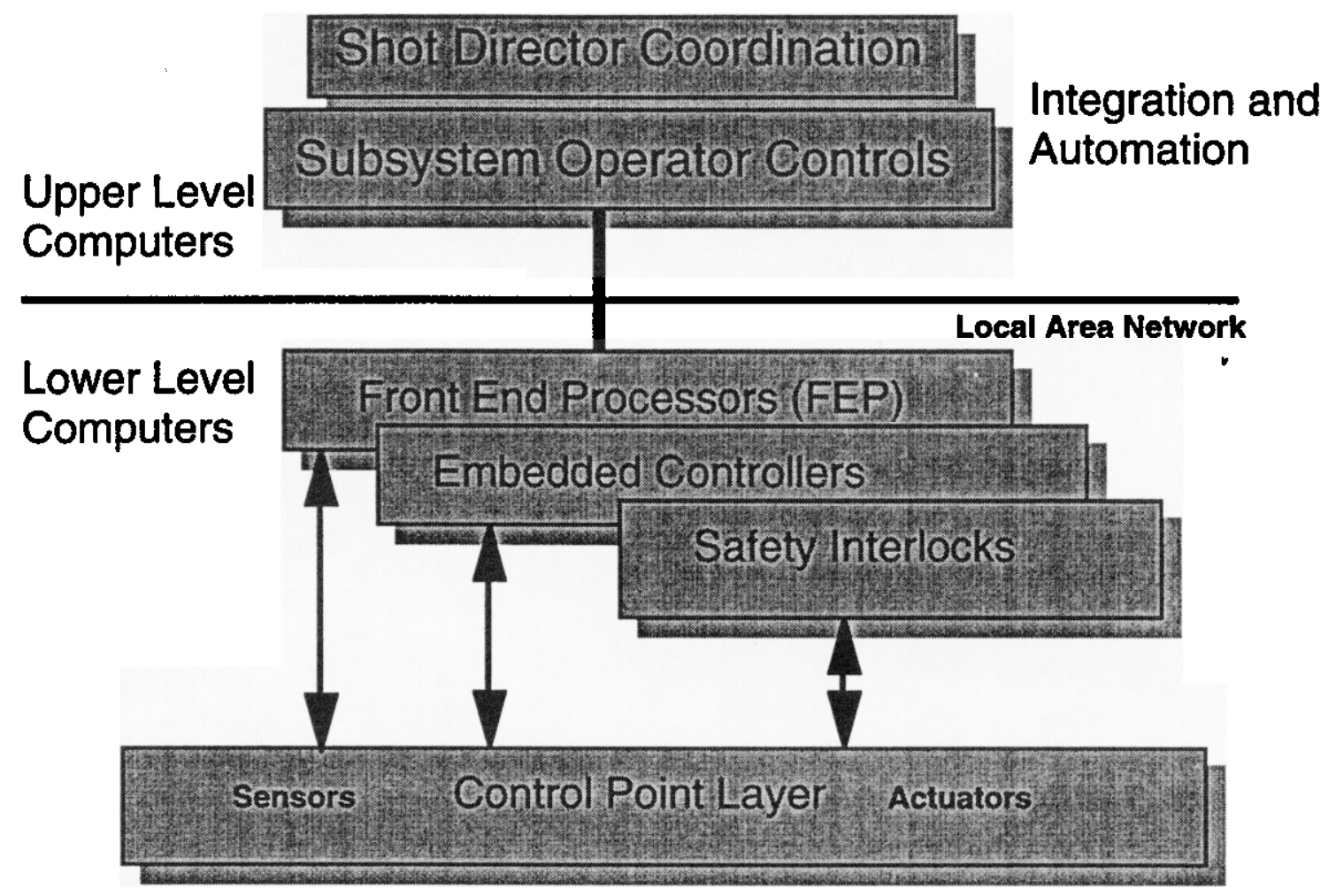




\subsubsection{Computer System Network}

(Figure is conceptual and quantities are subject to change in Title 2 design.)

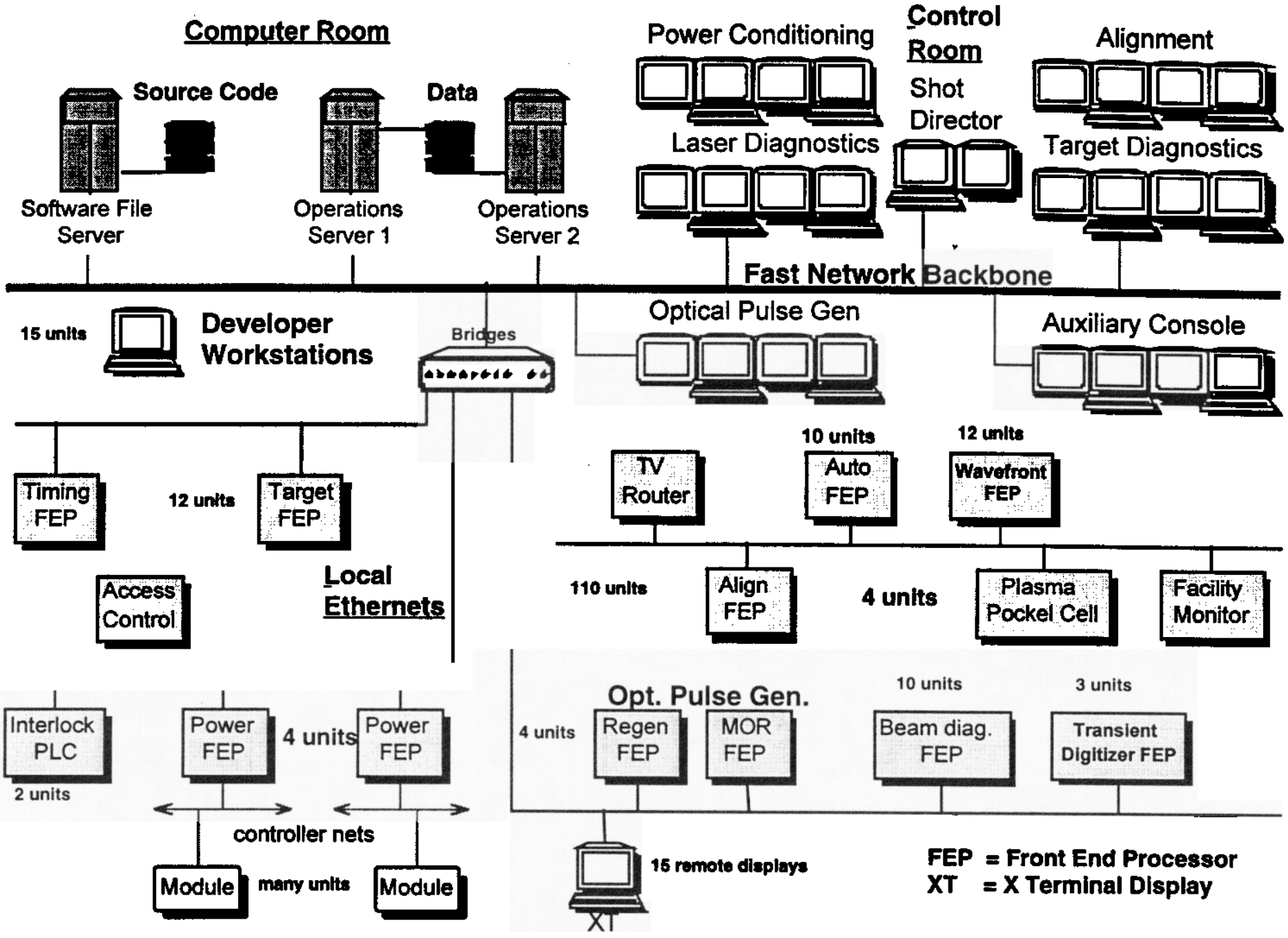




\subsubsection{Control Room Layout}

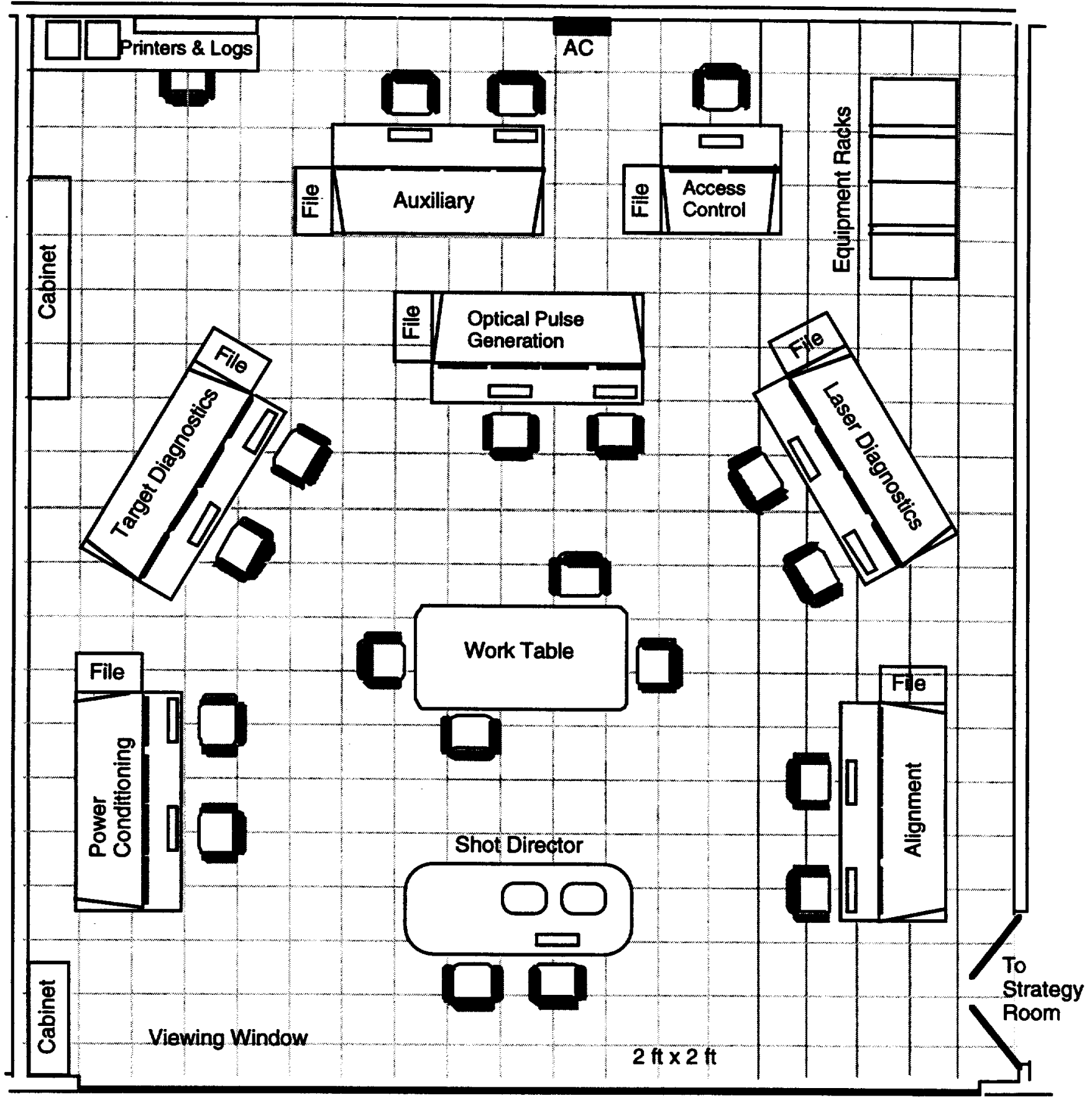




\subsubsection{Computer Room Layout}

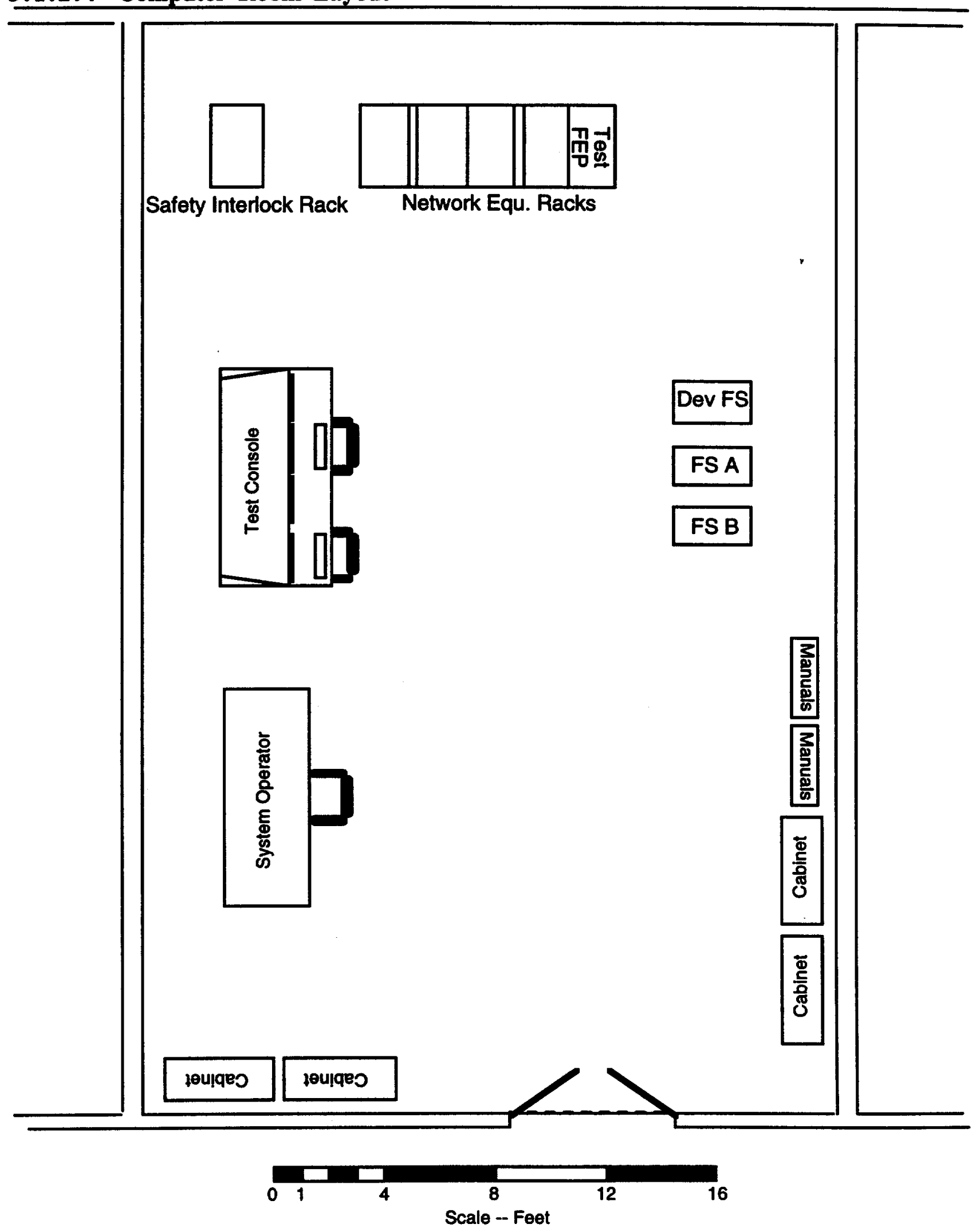




\subsubsection{Operator Console Layout}

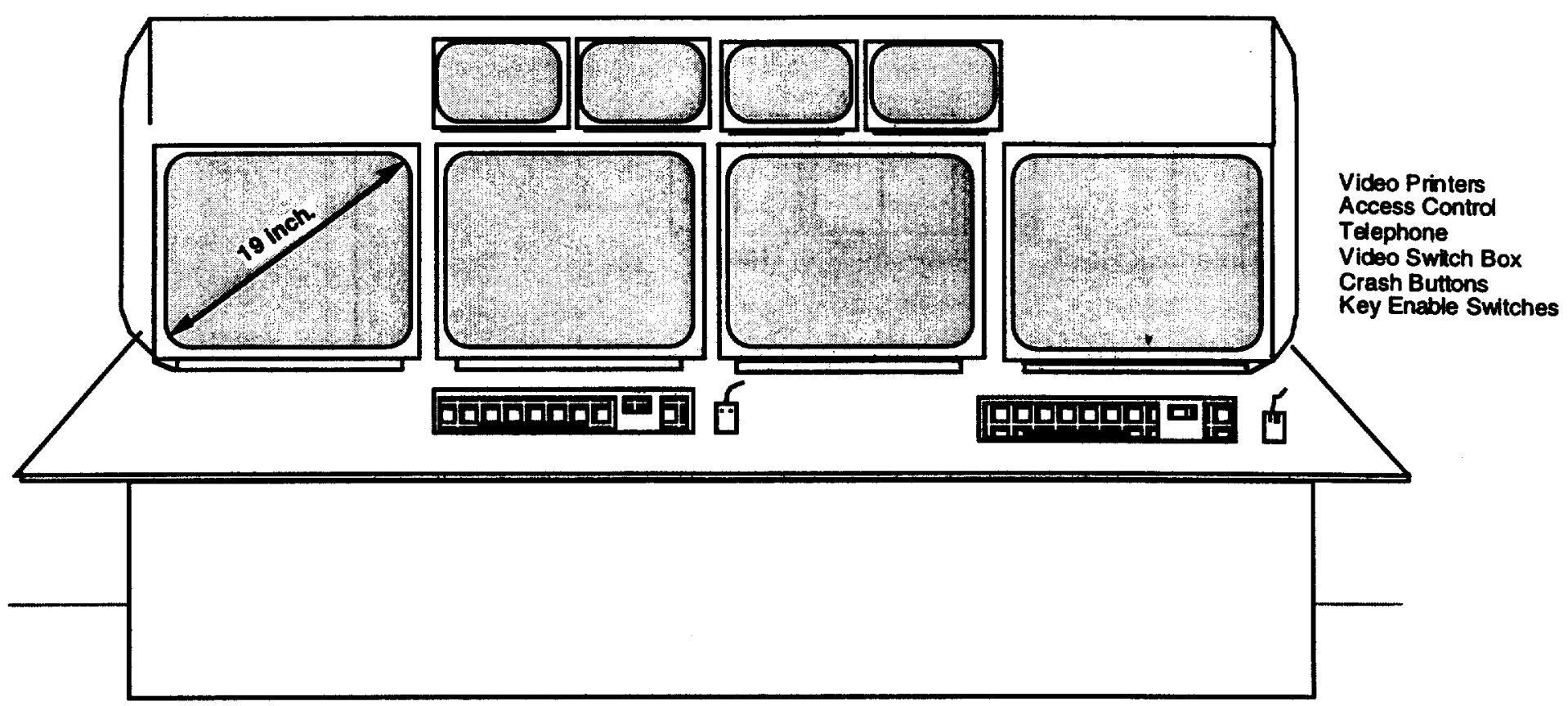

\subsubsection{System Interfaces}

The ICCS Computer System has interfaces to the following WBS systems:

WBS 1.5 .2

WBS 1.5.3

WBS 1.5.4.1

WBS 1.5 .5

WBS 1.5 .6 .1

WBS 1.5.6.3

WBS 1.8.3.11

WBS 1.7 .3

WBS 1.7 .2

WBS 1.7 .1

WBS 1.3.4

WBS 1.3.3

WBS 1.3.1

WBS 1.3 .1

WBS 1.3.1.1

WBS 1.3.1.5
Supervisory Software (computer hardware)

Integrated Timing System (network)

Integrated Safety System(network)

- Automatic Alignment (network)

Video Distribution (network)

Environmental Monitor (network)

Target Diagnostics Control Room(network)

Wavefront Control (network)

Beam Diagnostics (network)

Alignment Systems (network)

Power Conditioning (network)

Pockels Cell System (network)

OPG (network)

OPG Modulator (network)

OPG in MOR (network)

OPG/Preamp (network)

\subsubsection{Major Subsystems}

Consists of WBS 1.5.1.1 (Software Engineering Computer) system used for software development, and WBS 1.5.1.2 (Operations Computer System). 


\subsubsection{Functional Requirements}

The Computer System shall provide:

- upper-level computers: file servers, disk storage, workstations

- software development environment to include:

- operating system

- languages and software engineering tools

- graphical user interface (GUI) design and other tools

- database tools

- software configuration management

- $\quad$ software archival storage

- provide graphical operator consoles for rapid assessment of system status and input of controlcommands

- temporary shot data storage

- control room operator consoles and remote stations located near laser- and target-area subsystems

- local area network to connect all upper- and lower-level computers and FEPs, distribution system,

filtering bridges

- provide computational capability for routine data reduction and quick-look analysis

\subsubsection{Console Ergonomics}

Control and monitoring consoles located in the control room shall be ergonomically designed to maximize the efficiency of the operators and minimize strain associated with computer workstations.

\subsubsection{Computer System, Operating System}

The Computer System shall provide UNIX as the standard operating system platform for Supervisory and Front End Processor software.

\subsubsection{Computer Networks}

\subsubsection{Facility Wide Computer Network}

A facility-wide data network shall be provided as the backbone for data communications in NIF. Connecting to this backbone system are several or local area networks. Subsystems with related control and data dependence shall be closely coupled on separately bridged and isolated segments to achieve the desired performance and information transfer rates.

The Computer System shall provide a capacity planning analysis during Title 1, to plan and determine the network configuration.

\subsubsection{Computer Network, Safety Systems}

No Safety System related controls shall be operated over the facility wide computer network. Safety related systems shall operate over a network dedicated to safety related functions.

\subsubsection{Optical Communications Safety}

Where the Computer System uses lasers for optical communications, it shall conform to the applicable eye-hazard safety requirements to mitigate the possibility of eye exposure to an uncapped laser diode or unterminated active fiber source. Applicable standards include ANSI Z-136.1 (1993) and ANSI Z-136.2 (1988).

\subsubsection{Computer System and Network Reliability}

The computer system, with its integrated data communication network, shall meet the reliability standards for industrial grade control systems. Redundancy in the control system is not considered essential to achieve adequate reliability. Main computer system failures shall be repaired by the computer equipment vendor or equivalent repair service. These factors shall be controlled by the RAM allocation in paragraph 3.2.28 of this SSDR.

\subsubsection{GUI Support}

The Graphical User Interface (GUI) shall support a mouse or trackball input device and shall include a color and black/white hardcopy capability. 


\subsubsection{Network Performance, Average Latency}

Computer network performance shall provide a two-way (round-trip) average response time of less than 50 milliseconds.

\subsubsection{Network Performance, Maximum Response Time}

Computer network performance should provide a two-way (round-trip) maximum response time of less than 500 milliseconds under maximum network loading.

\subsubsection{Network Performance, Sustained Data Rate}

The computer network shall be capable of sustained throughput of greater than $100 \mathrm{Kbytes}$ per second to any single end point. This is to ensure good overall network throughput. The use of subnets, filtering bridges and/or switches is suggested to maintain these rates.

\subsubsection{Ethernet Loading}

Where Shared Ethernet is utilized in the computer network, the Ethernet average load shall be no greater than $15 \%$ of maximum over a shot cycle.

\subsubsection{GUI Computing Capacity, Interactive Device Update Performance}

The GUI (Graphical User Interface) shall support an average minimum of 10 status updates per second for one GUI window per operator display location.

\subsubsection{GUI Computing Capacity, Alarm and Exception Report Performance}

ICCS shall present an alarm and report update to the console operator in less than one second when used in an event driven mode. These alarms and reports shall be logged.

\subsubsection{GUI Computing Capacity, Broad View Update Performance}

When the operator console is being used to display status of the control system, typically acquired in a polling mode, the update response shall be less than 10 seconds. This response time is deemed to be a reasonable compromise between timely screen updates and excessive network traffic.

\subsubsection{Configuration}

There shall be two distinct computer systems, one for software development and one for operations. All software development shall be done on the development system. The only exception to this rule is development and testing of final operations scripts and system interaction testing shall be done on the operational computers but in a manner to not interfere with shot operations.

Installation of new software products shall follow a Configuration Management Plan and be coordinated with the operations staff.

\subsubsection{Shot Data Disk Storage Capacity}

On-line disk storage capacity shall be sufficient to store two weeks of shot data. The two week capacity provides a reasonable amount for on-line use (comparisons, setups, short term trends). This two week storage shall be rolled out to an archival storage facility or media on a weekly basis. This allows reasonable backup overlaps. One shot is expected to produce 60 megabytes of data.

\subsubsection{Shot Data On-line and Archived}

Two weeks after a shot, most experiment data will be rolled off to an archival storage media (where data integrity is guaranteed) and deleted from the laser computer system disks. However, laser performance and configuration data will be permanently kept on-line (in disk or other rapid access media) to allow quick performance comparisons of previously used laser configurations. Estimated configuration data quantity is 2.5 megabytes per shot. 


\subsubsection{Control Room Console Configuration}

The main control room console configuration shall consist of 5 main consoles: Alignment, Laser Diagnostics, Target Diagnostics, Power Conditioning, Optical Pulse Generation, one shot director console, an Access Control Console, and one auxiliary console. There also shall be a remote console in the Classified Control Room.

This accommodates a total of 10 operators plus a shot director with the Auxiliary Console as a spare.

\subsubsection{Console Graphics Standard}

The console graphics standard shall be "X11-R5" or later.

\subsubsection{Console System Flexibility}

Any console subsystem shall be capable of displaying and operating any control subsystem. In a distributed computing environment, flexible operations is required.

\subsubsection{Network Backbone}

A low latency, high data rate network shall make up the digital communication system backbone. The data rate of this backbone shall be at least 100 megabits/sec. Present candidates are FDDI, ATM and $100 \mathrm{Mbit} / \mathrm{sec}$ Ethernet. Other candidates are also possible. A survey and technical evaluation shall be made during Title 1 to determine this choice. Regardless of the choice, the physical cabling shall be configured in a hub-and-spoke (radial) fashion, to allow easier upgrades at a later date.

\subsubsection{LAN Subnets (Ethernet)}

The Computer System shall provide LAN subnets using $10 \mathrm{megabit} / \mathrm{sec}$ Ethernet, if latency and throughput is adequate. That is, FEP designers can expect to connect to a $10 \mathrm{megabit} / \mathrm{sec}$ Ethernet as the lowest common denominator network interface.

\subsubsection{Lower-Level Computer Attachment to LAN}

All computer equipment shall utilize network hardware and protocols compatible with the NIF network and bandwidth appropriate to the equipment requirements.

\subsubsection{Ethernet Protocol}

At a minimum, the network shall support TCP/IP as the network transport protocol.

\subsubsection{Graphics Software}

The graphic standard software shall be X-windows, X-toolkit and Motif. This means that the low-level (nonsupervisory) systems shall use the same standard as the console system.

\subsubsection{Computer Availability}

Mean time to repair (MTTR) for an individual computer shall be less than 4 hours, unless further restricted by RAM analysis and allocation. This time allows the use of standard, cost-effective, maintenance contracts.

\subsubsection{Computer System QA Level Requirements}

The Computer System shall adhere to the following Quality Level specifications:

Reference for QA Level is the NIF QA Plan as stated in paragraph 2.6 of this document.

WBS 1.5.1.1 Software Engineering Computer System

WBS 1.5.1.2 Operations Computer System

Q-Level 3

Q-Level 3

\subsubsection{Computer Availability, cold start}

Restarting all computers from a power-down condition shall take less than 30 minutes. This allows quick recovery from a power failure. 


\subsubsection{Computer System and Network, Lifetime, Replaceability and RAM}

\subsubsection{Computer System and Network, Lifetime}

Lifetime: The Computer System shall operate for 30 years.

\subsubsection{Computer System and Network, Replaceability}

Replaceability: Any portion of the Computer System which cannot reasonably be designed for 30 year lifetime shall be designed to be replaced or repaired at reasonable cost in a timely manner consistent with the overall availability of the System.

\subsubsection{Computer System and Network, Reliability}

The Computer System shall have an overall reliability of $99.94 \%$. Reliability is defined as the probability of meeting the minimum requirements of the experiment per no-yield shot.

\subsubsection{Computer System and Network, Availability}

The Computer System shall have a shot availability of at least $99.62 \%$. The ITS is unavailable when it is undergoing unplanned maintenance. Unplanned maintenance includes failure detection and active repair as well as logistic and administrative downtimes.

\subsubsection{Computer System and Network, Maintainability}

The Computer System shall have a scheduled maintenance plan that fits within an overall annual plant goal of 69 days. The unplanned maintenance goal is 1.0 days per year. Opportunistic maintenance activities are performed between shots and during other system downtimes.

\subsubsection{Environmental Requirements/EMI}

\subsubsection{Environmental Requirements, Temperature and Humidity}

The Computer System components shall be capable of operating in a standard commercial temperature and humidity of $5 \mathrm{C}$ to $40 \mathrm{C}$ (41 to 104F) and $20 \%$ to $80 \% \mathrm{RH}$ non-condensing when installed in their appropriate enclosures.

\subsubsection{Environmental Requirements, Plenum Approved/CL2 Cables} All. Computer System cabling installed in air plenums shall use plenum approved cabling. Otherwise controls cabling shall conform to CL2 specifications.

\subsubsection{Environmental Requirements, EMI Fields}

All Computer System electronic equipment shall be designed or purchased to tolerate, where warranted, an operating environment of $50 \mathrm{~V} / \mathrm{m}$ external electrical field and $0.1 \mathrm{~A} / \mathrm{m}$ external magnetic field without adverse effects. (ref ANSI C95.1-1991)

\subsubsection{Environmental Requirements, Ionizing Radiation}

Ionizing Radiation effects are an issue only inside the target room. Inside the target room careful consideration shall be given to the radiation and EMI effects as described in "Radiation and EMI Effects in the NIF Environment", UCRL-ID-118202.

\subsubsection{Human Factors}

The Computer System shall be designed in an ergonometric fashion to ensure that human reliability during operation and maintenance is sustained at a level consistent with meeting overall availability and reliability objectives. Consistency in displays, warnings, and human interfaces should be maintained throughout the Computer System and, if possible, throughout the NIF facility (i.e. GUI displays, access ports, tooling) 


\subsubsection{Recovery From Abnormal Event}

The time required for the Computer System to recover from any abnormal event shall be less than the maximum times cited below, as a function of the expected yearly frequency of occurrence of the event.

$\begin{array}{cc}\text { Expected Frequency of Occurrence Per Year, F } & \text { Maximum Recovery Time } \\ F \geq 1 & 24 \text { hours } \\ 1>F>1 e-2 & 1 \text { week } \\ 1 \mathrm{l}-2>\mathrm{F} \geq 5 \mathrm{e}-4 & 3 \text { months }\end{array}$

Probabilities listed in DOE-STD-1020-94 shall be used for natural phenomena.

For frequent events, the maximum allowed recovery time may be restricted by availability requirements to be less than that shown in the table above.

\subsubsection{Documentation and Records}

The Computer System shall provide sufficient documentation to comply with the NIF Quality Assurance Plan, and DOE Order 5700.6C, Quality Assurance, Criterion-4 Documents and Records, which states: "Documents shall be prepared, reviewed, approved, issued, used and revised to proscribe processes, specify requirements or establish design. Records shall be specified, prepared, reviewed approved and maintained."

Examples of documents that should be controlled include drawings, data files, calculations, specifications, computer codes, purchase orders, vendor supplied documents, procedures, work records and data sheets and test records. Revisions should be reviewed by the organizations that originally prepared and approved the documents. Controlled documents should be distributed to those doing the work.

\subsubsection{Computer Security}

The Computer System shall provide and operate under a LLNL/DOE approved unclassified computer security plan.

\subsection{Logistics}

\subsubsection{Maintenance}

As a part of the design/construction project, the Computer System shall provide all equipment required to inspect, service, and maintain all subsystems within the Computer System to meet the maintainability and availability requirements. Maintenance equipment shall include all handling fixtures, lifting equipment, and other special tools not otherwise available within the NIF, that are necessary to perform any planned (scheduled or unscheduled) maintenance activity.

\subsubsection{Spares}

As a part of the design/construction project, the Computer System shall provide an initial compliment of spare parts as required to activate the system. 


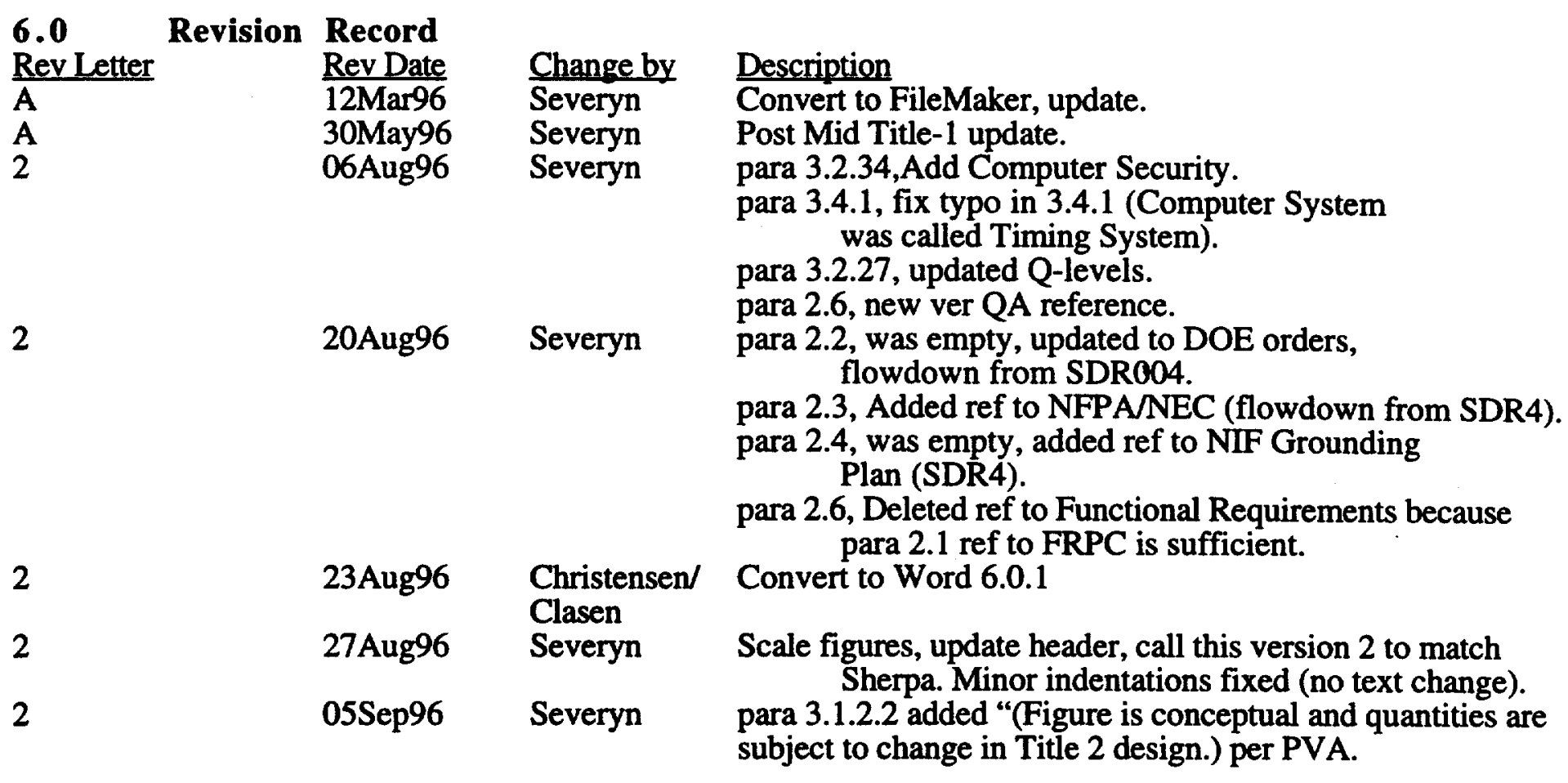




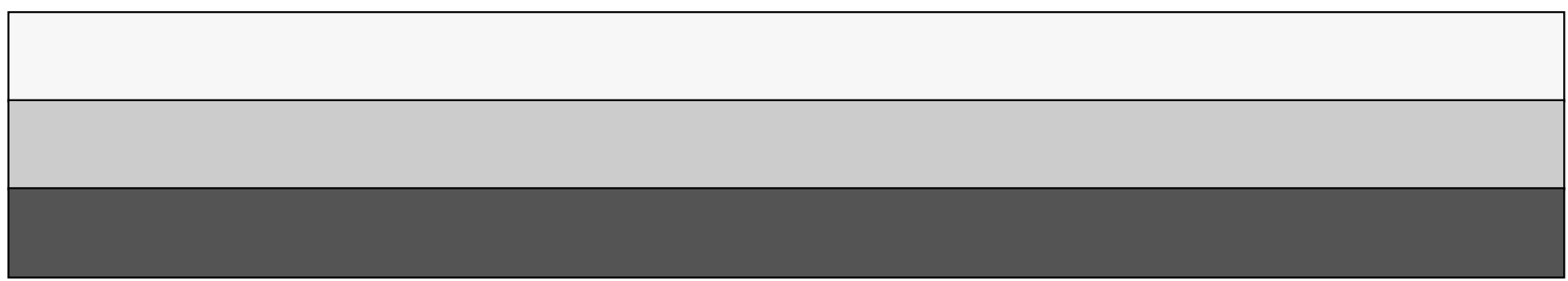

